\title{
Bone Mineral Density in Children with Juvenile Idiopathic Arthritis: A Hospital Based Study
}

\author{
MUHAMMAD FUADUL ISLAM ${ }^{1}$, MOHAMMAD IMNUL ISLAM ${ }^{2}$, MANIK KUMAR TALUKDAR ${ }^{2}$ \\ SHAHANA A RAHMAN ${ }^{3}$
}

\begin{abstract}
:
Background: Failure to develop adequate bone mineralization is common in children with Juvenile Idiopathic Arthritis (JIA). Osteopenia or osteoporosis occurs in all the JIA subtype but particularly common in systemic onset and polyarticular JIA. There is an association of increased demineralization of bones with duration of joint disease.
\end{abstract}

Objective: To determine the extent of osteoporosis in Juvenile Idiopathic Arthritis (JIA).

Methodology: Cross sectional study conducted from July 2011 to December2011 in
Department of Paediatrics and Institute for Nuclear Medicine and Ultrasound(INMU),
Bangabandhu Sheikh Mujib Medical University (BSMMU), Dhaka.

Participants: Total 30 patients were enrolled in this study.

Results: Significant osteopenia among 53.33\% and 70\% JIA patients and osteoporosis among $26.67 \%$ and $23.33 \%$ JIA patients were found at femur neck and lumber region respectively. In polyarticular cases majority of the cases had osteopenia (81.25\% and $75 \%$ ) and in systemic onset JIA cases majority had osteoporosis (55.56\% and $33.37 \%$ ) at femur neck and lumber region respectively. Longer duration cases at diagnosis had more osteopenia (58.33\% and 66.67\%) and osteoporosis (41.67\% and $33.33 \%)$ than the shorter duration cases at femur neck and lumber region respectively.

Conclusion: From this small pilot study it may be concluded that JIA Patients are likely to have low BMD. Among them polyarticular and systemic onset JIA patients are even more susceptible to low BMD. There is also positive relationship between the duration of arthritis and low BMD.

\section{Introduction:}

Failure to develop adequate bone mineralization is common in children with JIA ${ }^{1}$. Osteopenia is a condition where bone mineral is lower than normal. Osteoporosis is characterized by loss of both bone mass and micro architectural integrity resulting in an increased risk of fracture, growth retardation with associated morbidity and mortality ${ }^{2}$. Osteopenia and or osteoporosis occur in all of the JIA subtype and most commonly found in systemic and polyarticular disease ${ }^{3}$. Osteopenia is a bone condition characterized by a decreased density of bone, which leads to bone weakening and an increased risk of fracture ${ }^{3}$.

1. FCPS Student, BSMMU

2. Assistant Professor, Paediatric Department, BSMMU.

3. Professor, Paediatrics, BSMMU.

Correspondence: Dr. Muhammad Fuadul Islam, FCPS student, BSMMU, Email-fuadislam96@yahoo.com
Pathophysiology of bone loss is multifactorial and involves excessive activation of osteoclastogenesis and reduction of bone formation. Decreased physical activity, nutritional insufficiency, increased cytokines and drugs such as steroids and MTX negatively affect the skeletal maturation ${ }^{4-5}$. In a cross- sectional study, low bone mineral density (BMD) was found in $40-52 \%$ of JIA patient ${ }^{6}$.

A bone mineral density (BMD) measurement is the best way to determine osteopenia and osteoporosis ${ }^{7}$. BMD test can identify osteopenia and osteoporosis, determine the risk of fracture, assess growth retardation and measure the response to treatment. There is an association of increased demineralization of bones with duration of joint disease ${ }^{8}$.

In Bangladesh majority of JIA patients are diagnosed with long duration of disease ${ }^{9}$. No study regarding BMD in JIA so far has been done to assess the bone mineral density in the JIA patients. 
This study was conducted with the objective of determining the bone mineral density (BMD) in JIA patients. The study also assessed the extent of BMD in different types of JIA and to assess the relationship of BMD with duration of illness.

\section{Methodology:}

This was a cross sectional study done in the department of Paediatrics and Intitute for Nuclear Medicine and Ultrasound (INMU), Bangabandhu Sheikh Mujib Medical University, Dhaka from July 2011 to December 2011. Thirty newly diagnosed cases of JIA according to International League against Rheumatism (ILAR) classification, whose age group between 4- 16 years,were included in the study. Consent was taken from the parents/attendance before enrolling their child in the study. Ten healthy children without any chronic disease or bone disease of similar age group were taken as control. Control was taken as no data was available in the Institute for Nuclear Medicine and Ultrasound, BSMMU for reference population below 20 years which can be compared with study population. Patients previously treated with DMARD'S or steroids were excluded from the study. Age group below 4 years was excluded from study as measurement of BMD was not possible with the existing BMD machine.

Demographic data and clinical characteristics were recorded. Necessary investigations were done. Bone mineral density (BMD) of the patients was measured at femur neck and lumber spine by dual energy $x$-ray absorbtiometry (DXA) manufactured by NORLAND, a cooper surgical company, model no 4/00. Result was reported as T-scores which represent the number of standard deviations (SD) from the mean bone density values of the controls. Normal reference was calculated from the bone mineral density in $\mathrm{gm} / \mathrm{cm}^{2}$ of the control group (Table-I).

From Table-I, average reference bone mineral density of control group at femur neck was calculated as $0.7652 \mathrm{gm} / \mathrm{cm}^{2}$ and reference at L1-L4 was calculated as $0.7827 \mathrm{gm} / \mathrm{cm}^{2}$ respectively.

$\mathrm{T}$ - Score was calculated by using the following formula:

\section{T-score $=(B M D-$ reference BMD $) / S D$}

BMD of different types of JIA patients were observed. Any relationship with duration of illness and BMD was also observed. According to $\mathrm{WHO}$ guidelines T score of 0 to -1 indicated normal, -1 to -2.5 indicated osteopenia and less than -2.5 indicated osteoporosis.
Analysis of data including calculation of T-score, percentage and comparison was done manually.

\section{Results:}

30 newly diagnosed cases of JIA whose age group in between 4-16 years were enrolled in this study. Among them male were 20, and female were 10, Male: Female $2: 1$. When JIA patients were classified according to ILAR criteria it was found that oligoarticular $05(16.7 \%)$, Poly articular16 (53\%) and systemic onset 09 (30.3\%).

Table- I shows that average reference bone mineral density of control group at femur neck was calculated as $0.7652 \mathrm{gm} / \mathrm{cm} 2$ and reference at L1-L4 was calculated as $0.7827 \mathrm{gm} / \mathrm{cm} 2$.

Table-I

Bone mineral density of control group. $(n-10)$

\begin{tabular}{|c|c|c|}
\hline \multirow[t]{2}{*}{ SI. No. } & \multicolumn{2}{|c|}{ Bone Mineral Density $\mathrm{gm} / \mathrm{cm}^{2}$} \\
\hline & Femur Neck region & $\mathrm{L}_{1}-\mathrm{L}_{4}$ region \\
\hline 01 & 0.7837 & 0.8165 \\
\hline 02 & 0.6758 & 0.7904 \\
\hline 03 & 0.7974 & 0.8375 \\
\hline 04 & 0.7782 & 0.6955 \\
\hline 05 & 0.7737 & 0.8265 \\
\hline 06 & 0.6857 & 0.7804 \\
\hline 07 & 0.7994 & 0.8575 \\
\hline 08 & 0.7789 & 0.6855 \\
\hline 09 & 0.8037 & 0.7565 \\
\hline 10 & 0.7758 & 0.7804 \\
\hline Average & 0.7652 & 0.7827 \\
\hline
\end{tabular}

Table-Il shows the duration of illness at diagnosis. Duration of illness was more than 1year in the majority $(40 \%)$ of the cases followed by 6 months to 1 year $(33.33 \%)$ and 6 wks to 6 month $(26.67 \%)$.

Table-II

Duration of illness at diagnosis ( $n-30)$

\begin{tabular}{lcc}
\hline Duration of illness & Number & Percentage \% \\
\hline 6wk to 6month & 08 & 26.67 \\
6 Month to 1yr & 10 & 33.33 \\
> 1yr & 12 & 40.00 \\
\hline Total & 30 & 100 \\
\hline
\end{tabular}


Table-III

BMD Score of study cases at neck of the femur and lumber region: (n-30)

\begin{tabular}{lccc}
\hline BMD score at femur neck & Number (\%) & BMD score at lumber spine & Number \% \\
\hline 0 to -1 & $06(20)$ & 0 to -1 & $02(6.67)$ \\
-1 to -2.5 & $16(53.33)$ & -1 to -2.5 & $21(70 \%)$ \\
>-2.5 & $08(26.67)$ & $>-2.5$ & $07(23.33)$ \\
\hline
\end{tabular}

Table-IV

Extent of BMD in different types of JIA $(n=30)$

\begin{tabular}{lcccccc}
\hline Clinical type & \multicolumn{3}{c}{ BMD at Femur Neck } & \multicolumn{3}{c}{ BMD at lumbar Spine } \\
& 0 t0 -1 & -1 to -2.5 & $<-2.5$ & 0 to -1 & -1 to -2.5 & $<-2.5$ \\
\hline Oligoarticular $(n=5)$ & $04(80 \%)$ & 00 & $01(20 \%)$ & $02(40 \%)$ & $03(60 \%)$ & 00 \\
Polyarticular $(n=16)$ & $01(6.25 \%)$ & $13(81.25 \%)$ & $02(12.5 \%)$ & 00 & $12(75 \%)$ & $04(20 \%)$ \\
Systemic Onset $(n=9)$ & $01(6.25 \%)$ & $03(33.33 \%)$ & $05(55.56 \%)$ & 00 & $06(66.67 \%)$ & $03(33.37 \%)$ \\
\hline
\end{tabular}

Table-V

Relationship of BMD with duration of illness $(n=30)$

\begin{tabular}{lcccccc}
\hline Duration of illness & \multicolumn{3}{c}{ BMD at Femur Neck } & \multicolumn{3}{c}{ BMD at lumbar Spine } \\
& 0 t0 -1 & -1 to -2.5 & $<-2.5$ & 0 to -1 & -1 to -2.5 & $<-2.5$ \\
\hline $\begin{array}{l}6 \text { weeks to 6 months } \\
(n=08)\end{array}$ & $04(80 \%)$ & $04(50 \%)$ & 0 & $01(16.7 \%)$ & $06(75 \%)$ & $01(16.7 \%)$ \\
$\begin{array}{l}6 \text { months to 1 year } \\
(n=10)\end{array}$ & $02(20 \%)$ & $05(50 \%)$ & $03(30 \%)$ & $01(10 \%)$ & $07(77 \%)$ & $02(20 \%)$ \\
$>1$ year (n=12) & 0 & $07(58.3 \%)$ & $07(58.3 \%)$ & 0 & $08(66.7 \%)$ & $04(33.3 \%)$ \\
\hline
\end{tabular}

Table- III shows that most of the patients had osteopenia at lumbar spine and femur neck region (70\% and $53.33 \%$ ). Osteoporosis was found in $23.33 \%$ and $26.67 \%$ patients in lumbar spine and femur neck respectively.

Table - IV shows the extent of BMD in different types of JIA. It was found that most of the oligoarticular cases $(80 \%$ and $40 \%)$ had normal BMD scores at femur neck and lumber region. But the majority of the polyarticular cases (81.25\% and $75 \%$ ) had osteopenia at femur neck and lumber region. Most of the systemic onset patients had osteoporosis at femur neck $(55.56 \%)$ and osteopenia at lumber region (66.67\%).

Table- $\mathrm{V}$ represents the relationship of BMD with duration of Illness. It was found that $50 \%$ and $70 \%$ of the patients in 6 month to 1 year duration group and $58.33 \%$ and $66.67 \%$ of more than $1 \mathrm{yr}$ duration group had osteopenia at femur neck and lumber region respectably. Among the short duration cases (6weeks to 6 months) no patient at femur neck and only $16.67 \%$ at lumber region had osteoporosis but among the longer duration cases (>1 year) $58.3 \%$ and $33.33 \%$ had osteoporosis and no patient had normal BMD.

\section{Discussion}

The present study was carried out to assess the bone mineral density among the Juvenile idiopathic arthritis patients, attending the pediatric rheumatology clinic, Bangabundhu Shekh Mujib Medical University (BSMMU).

Among the 30 study cases $66.67 \%$ were male and $33.4 \%$ were female, male female ratio being $2: 1$. Miller et al ${ }^{10}$ found that females are always predominant among the JIA patients but our study found the reverse result. This might be due to our socio-cultural background where male children are given more importance and care. Rahman et al ${ }^{11}$ and Islam et $\mathrm{al}^{12}$ also found male predominence in their study. 
Among the 30 patient, most of them (40\%) were suffering for longer duration (more than $1 \mathrm{yr}$ ), $33.33 \%$ patients were suffering from 6 month to $1 \mathrm{yr}$ and $26.67 \%$ were suffering from 6 wk to 6 month. Rahman et al also showed similar findings where duration of arthritis at diagnosis was more than 1year in the majority of the cases. ${ }^{11}$

It was found that, BMD score was in between -1 to -2.5 in $53.33 \%$ of all JIA cases at femur neck and in $70 \%$ of cases at $L_{1}-L_{4}$ region respectively. Similarly BMD score was less than -2.5 in $26.67 \%$ cases at femur neck and in $23.33 \%$ at $L_{1}-L_{4}$ region respectively. Pep Muller et al in their study found similar findings where there was decreased $B M D$ at $L_{1}-L_{4}$ region in $J I A .{ }^{13}$

The study also tried to find out the extent of osteoporosis in different types of JIA.It was found that among the 16 polyarticular patients $6.25 \%$ had normal BMD at femur neck. But $81.25 \%$ and $75 \%$ patient had osteopenia, and $2.5 \%$ and $18.75 \%$ patients had osteoporoses at femur neck \& lumber region respectively. Zak et al found similar finding where there was low BMD in $40-52 \%$ JIA patient, where polyarticular type predominated. ${ }^{6}$ Among the 09 systemic onset JIA cases, $11.11 \%$ had normal BMD. But $33.33 \%$ and $66.67 \%$ had osteopenia and 55.56 and $33.35 \%$ had osteoporosis in femur neck\& lumber region respectively. So, the present study found mostly osteopenia in polyarticular patients and mostly osteoporosis in systemic onset JIA patients. This finding was also consistent with reported results where systemic onset and polyarticular cases had more osteopenia and osteoporosis ${ }^{3}$.

In this study BMD results were also compared with the duration of illness at diagnosis. $50 \%$ of the patients in 6 month to 1 year duration group and $58.33 \%$ of more than $1 \mathrm{yr}$ duration group had osteopenia at femur neck.Among the short duration cases (6weeks to 6 months) no patients had osteoporosis but longer duration cases (>1 year) $41.67 \%$ had osteoporosis and no patient had normal BMD. Similarly at $L_{1}$ to $L_{4}$ region longer duration cases had more osteoporosis and none of them had normal BMD. This findings is consistent with the study done by Boman et al who found duration of arthritis to be positively correlated with low BMD. ${ }^{8}$

\section{Conclusion:}

From this small pilot study it may be concluded that JIA Patients are likely to have low BMD. Among them polyarticular and systemic onset JIA patients are more susceptible to lowBMD. There is also positive relationship between the duration of arthritis and low BMD.

\section{References:}

1. Climaz R, Falcini F. Skeletal maturation and bone mineralization in the pediatric Rheumatic disease. In: Cassidy JT, Petty RE, Laxer RM, Lindsley CB, editors. Textbook of Pediatric Rheumatology. $6^{\text {th }}$ edn.Philadelphia: Elsevier Saunders; 2010. 730-41.

2. Cassidy JT, Hillman LS. Abnormalities in skeletal growth in children with JIA. Rheum Dis Clin North Am 1997; 23: 499-522.

3. Pepmueller $\mathrm{PH}$, Cassidy JT, Allen $\mathrm{SH}$, and Hilman LS, Bone mineralization and Bone mineral metabolism in children with juvenile rheumatoid arthritis.Arthritis \& Rheum 1996; 39: 746-57.

4. Giannini HE, Cawkwell GT. Drug treatment in children with juvenile rheumatoid arthritis. PediatrClin North Am 1995; 42: 1099-1125

5. Warady BD. Lindsley CB, Robinson FG. The effect of nutritional supplementation on bone mineral status of children with rheumatic diseases on corticosteroid therapy. J. Rheumatol 1994; 21: 530-35

6. Zak M, Hassager C, Lovell DJ, Nielsen S, Henderson CJ, Pedersen FK. Assessment of bone mineral density in adults with a history of juvenile chronic arthritis: a cross sectional longterm follow up study, J. Rheumatol 1999; 142: 790-98.

7. Wang SJ, Yang YH, Lin YT, Yang CM, Chiang BL. Attained adult height in juvenile rheumatoid arthritis with or without corticosteroid treatment. J. Rheumatol 2002; 21: 363-68.

8. Boman P, Babaoglu S, Gur G, Bingol S, Bodur $\mathrm{H}$. Bone mineral density and bone turn over in patientswith psoriatic arthritis. Clin Rheumatol 2008; 27: 443-47.

9. Rahman SA, Islam MI, Hossoin M, Talukder MK. Clinical presentation of JIA in Bangladesh. International journal of Rheumatic disease. 2008; 11: 50-54.

10. Miller ML, Cassidy JT. Juvenile Rheumatoid Arthritis; Richard E. Behraman, Robert M. Kliegman, Hal B. Jenson, editors. Nelson textbook of Pediatrics, $17^{\text {th }}$ edition. India: Saunders; 2004. P. 799-805.

11. Islam MI, Hossoin M, Talukder MK, Begum JA, Rahman SA. Responsiveness of outcome measure in JIA patients treated with MTX. Bangladesh J. Child Health, 2008; 32:1-5.

12. Pepmueller P, KietzD, Moore T. Clinical response to etanercept in poly-articular course juvenile rheumatoid arthritis. J Rheumatol 2001; 28:360-2. 